\title{
Understanding and Exercise of Gluteus Medius Weakness: A Systematic Review
}

\author{
Seung-min Baik ${ }^{1,2}$, PT, BPT, Heon-seock Cynn¹, PT, PhD, Seok-hyun Kim¹, PT, BPT \\ ${ }^{1}$ Applied Kinesiology and Ergonomic Technology Laboratory, Department of Physical Therapy, The Graduate School, Yonsei University, \\ Wonju, ${ }^{2}$ Division of Health Science, Department of Physical Therapy, Baekseok University, Cheonan, Korea
}

\author{
Article Info \\ Received January 5, 2021 \\ Revised January 12, 2021 \\ Accepted January 13, 2021 \\ Corresponding Author \\ Heon-seock Cynn \\ E-mail: cynn@yonsei.ac.kr \\ https://orcid.org/0000-0002-5810-2371
}

\section{Key Words}

Exercise

Gluteus medius weakness

Hip abductor muscles

\begin{abstract}
A weak or dysfunctional gluteus medius (Gmed) is related to several pathologies, and individuals with hip abductor weakness have Gmed weakness. This study aimed to systematically review the literature associated with the anatomy and function of the Gmed, and the prevalence, pathology, and exercise of Gmed weakness. Papers published between 2010 and 2020 were retrieved from MEDLINE, Google Academic Search, and Research Information Sharing Service. The database search used the following terms: (glut* OR medius OR hip abduct*) AND weak*. The Gmed plays an important role in several functional activities as a primary hip abductor by providing pelvic stabilization and controlling hip adduction and internal rotation. Weakness of the Gmed is associated with many disorders including balance deficit, gait and running disorders, femoroacetabular impingement, snapping hip, gluteal tendinopathy, patellofemoral pain syndrome, osteoarthritis, iliotibial band syndrome, anterior cruciate ligament injury, ankle joint injuries, low back pain, stroke, and nocturia. Overuse of the tensor fasciae latae (TFL) as a hip abductor due to Gmed weakness can also cause several pathologies such as pain in the lower back and hip and degenerative hip joint pathology, which are associated with dominant TFL. Similarly, lateral instability and impaired movements such as lumbar spine lateral flexion or lateral tilt of the pelvis can occur due to compensatory activation of the quadratus lumborum for a weakened Gmed while exercising. Therefore, the related activation of synergistic muscles or compensatory movement should be considered when prescribing Gmed strengthening exercises.
\end{abstract}

\section{INTRODUCTION}

The gluteus medius (Gmed), gluteus minimus, and tensor fasciae latae (TFL) muscles are hip abductors, and sufficient strength of these muscles is associated with the maintenance of stability during gait [1]. The Gmed is a primary hip abductor muscle that provides pelvic stabilization in a unilateral stance against gravity, and eccentrically controls hip adduction and internal rotation [2]. Weakness of Gmed results in compensatory motion of the lower back, hip, and knee, and all individuals with hip abductor weakness have Gmed weakness [3].

Weakness or dysfunction of the Gmed is associated with a variety of disorders, including balance deficit [4], gait and running disorders [1,5-16], hip joint [11,16-20], knee joint [10,15,21-34], and ankle joint pathologies [35,36], and several other disorders [20,37-47]. Therefore, hip abduction strength- ening may be crucial for rehabilitation and injury-prevention strategies [1].

Hip abduction or Gmed strengthening exercises may improve pain [10,30,38,48], physical function [10,30], abnormal movement patterns [49], and symptoms related to these disorders $[11,48]$ in individuals with Gmed weakness. However, when prescribing hip abduction strengthening exercise, one should consider factors such as synergistic dominance and compensatory movement $[2,3,22,50-52]$. For example, the TFL is one of the synergist muscles as a hip abductor, and overuse of the TFL can be triggered by Gmed weakness; this is described as synergistic dominance [22].

Therefore, to facilitate optimum hip abduction or Gmed strengthening exercise for individuals with Gmed weakness, sufficient understanding of Gmed weakness is required. The purpose of this study was to determine the exercise of individ- 
uals with Gmed weakness as well as study the anatomy, function, prevalence, and pathology of Gmed.

\section{SEARCH STRATEGY}

All literature published between 2010 and 2020 were obtained by undertaking a comprehensive search of electronic databases (MEDLINE, Google Academic Search, Research Information Sharing Service). The following combined and/or truncated search terms were used in each database: (glut* OR medius OR hip abduct*) AND weak*.

\section{ANATOMY AND FUNCTION OF THE GLUTEUS MEDIUS}

The Gmed is attached proximally to the external surface of the ilium above the gluteal line and distally attached onto the lateral aspect of the greater trochanter [53]. The Gmed has three sets of functional fibers: anterior, middle, and posterior [53]. Anatomically, Gmed is the largest abductor of the femur from the pelvis, accounting for $60 \%$ of the total abductor crosssectional area and leg abduction to the tibia is caused by other abductors such as TFL and gluteus maximus [8,53]. In particular, the posterior fibers of Gmed also act as external rotators of the hip [8].

The Gmed (especially the posterior fibers) controls femoral adduction and stabilize the pelvis by counteracting gravity during dynamic lower-extremity motion [2,50,54]. For example, at foot contact during gait when the femur is adducted in relation to the pelvis, Gmed contracts concentrically after undergoing eccentric contraction immediately before that, during a support phase; therefore, hip abduction occurs during the propulsive phase $[8,48]$. This activation of the Gmed during single-limb support also prevents the body from falling to the unsupported side [8].

\section{PREVALENCE AND PATHOLOGY OF GLUTEUS MEDIUS WEAKNESS}

\section{Balance, Gait, and Running}

\section{1) Balance}

Lee and Powers [4] reported diminished postural stability represented by an increase in the medial-lateral center of pressure displacement observed in individuals with relatively lower hip abductor strength. Specifically, individuals with relatively weak hip abductors showed increased utilization of an ankle strategy with decreased medial-lateral postural stability during unipedal static standing and unipedal dynamic step-down balance task [4].

\section{2) Gait}

Traditionally, impaired function of the hip abductors was considered the cause of the Trendelenburg gait, which is characterized by an excessive pelvic drop towards the contralateral side [7,8]. Van der Krogt et al. [9] reported that normal gait was possible by removing most muscles, but not possible with weakened Gmed or plantar flexors. Clinically, Vandekerckhove et al. [6] reported that among the hip joint muscles, strength in the abductors was found to be the most important for the performance of several gait patterns in patients with cerebral palsy, and Iijima et al. [10] reported that osteoarthritis patients with reduced hip abductor strength demonstrated lower turning speed. However, Pohl et al. [5] reported that no alterations in hip adduction moment, hip adduction, or contralateral pelvic drop were associated with reduced hip abductor strength in young, healthy men. Other studies also reported that no significant pelvic drop was detected in even severe hip abductor weakness; therefore hip abductor weakness is not enough to explain the Trendelenburg sign [38,55].

\section{3) Running}

Taylor-Haas et al. [14] reported that isokinetic hip abduction torque was negatively associated with hip adduction range of motion during running in young adult and adolescent male long-distance runners. However, more recent studies showed that isometric or eccentric hip abductor muscle strength was not associated with the peak hip adduction angle during running in healthy female runners [12,56]. Radzak and Stickley [1] also reported that there was no association between hip abduction weakness resulting from fatigue after a run and an increased hip adduction angle during running in healthy, physically active males.

\section{Hip Joint}

\section{1) Femoroacetabular impingement}

In a case-control study by Frasson et al. [19], there was no statistically significant difference in isometric hip abductor strength between males with femoroacetabular syndrome and 
healthy male controls. However, Casartelli et al. [17] and Diamond et al. [18] reported that patients with symptomatic femoroacetabular impingement had significantly weaker isometric hip abductor muscle strength than healthy control group.

\section{2) Snapping hip}

Jacobsen et al. [16] reported significant muscle strength impairments, activity limitations, and participation restrictions in patients with symptomatic snapping hip compared with healthy controls.

\section{3) Gluteal tendinopathy}

In a previous study by Allison et al. [11], individuals with symptomatic gluteal tendinopathy showed significantly weaker isometric hip abductor strength than those in the asymptomatic control group, and the side-to-side difference in isometric hip abductor strength was significantly greater in the symptomatic group than in the asymptomatic group.

\section{Knee Joint}

\section{1) Patellofemoral pain syndrome}

Previous studies reached no consensus about the association between patellofemoral pain syndrome and hip abductor weakness. Ferber et al. [23] reported that runners with patellofemoral pain syndrome had significantly weaker isometric hip abduction strength than healthy controls while female runners and novice runnners in other studies showed no difference in isometric hip abduction strength compared to asymptomatic runners [57,58]. Nakagawa et al. [25] reported that individuals with patellofemoral pain syndrome showed significantly lower eccentric hip abduction torque than controls, while Bolgla et al. [24] and Hoglund et al. [59] reported that males with patellofemoral pain did not have significantly different peak isometric hip abduction strength compared to the controls. In addition, Herbst et al. [26] reported that female athletes with patellofemoral pain syndrome showed significantly greater concentric hip abduction strength than those in the control group.

\section{2) Osteoarthritis}

Weakness of the hip abductors and quadriceps muscle was considered a common feature in individuals with osteoarthritis [10]. Previous studies reported that individuals with osteoarthritis showed significantly weaker isometric or isokinetic hip abduction strength than the control groups $[28,30,31]$. In addition, hip abductor weakness related to osteoarthritis was found to cause functional activity limitation while ascending and descending stairs, walking, and rising from a chair [28,29,33].

\section{3) Iliotibial band syndrome}

Foch et al. [15] reported that female runners with current iliotibial band syndrome did not show significantly different isometric hip abductor strength compared to those who previously had iliotibial band syndrome or healthy controls. However, female runners with previous iliotibial band syndrome exhibited significantly lower hip abductor strength than controls [15].

\section{4) Anterior cruciate ligament injury}

In a prospective study by Khayambashi et al. [34], male and female athletes who sustained noncontact anterior cruciate injury exhibited significantly lower hip abduction strength compared with non-injured athletes. Regression analysis also showed that hip abduction strength was significantly associated with an increased risk of noncontact anterior cruciate ligament injury (odds ratio $=1.12[95 \%$ confidence interval, 1.05-1.20], $p=0.01$ ) [34].

\section{Ankle Joint}

Powers et al. [35] reported that injured male soccer players with noncontact lateral ankle sprains showed significantly lower hip abductor strength compared to uninjured players at baseline assessment. Reduced hip abductor strength was also associated with an increased risk of noncontact lateral ankle sprains in regression analysis (odds ratio $=1.10[95 \%$ confidence interval, 1.02-1.18], $\mathrm{p}=0.01$ ) [35].

Individuals with chronic ankle instability who commonly progress to lateral ankle sprain showed significantly lower isometric hip abduction strength compared to lateral ankle sprain copers (who had a history of lateral ankle sprain but no characteristics related to chronic ankle instability) and controls [36]. However, in a more recent study, McCann et al. [60] demonstrated that there were no significant differences in isometric hip abduction strength among chronic ankle instability, lateral ankle sprain copers, and control groups. 


\section{Others}

\section{1) Low back pain}

Several studies have demonstrated that isometric hip abduction strength was significantly lower in individuals with low back pain when compared to the controls $[20,38,39,61]$. In addition, subsequent hierarchical linear regression analysis demonstrated that Gmed weakness was one of the predictors of low back pain [20]. Patients with L5 radiculopathy also exhibited hip abductor weakness [41]. In particular, the posterior fibers of the Gmed are more prone to weakness than the anterior fibers in patients with chronic low back pain and Gmed weakness [42].

\section{2) Stroke}

Sánchez et al. [43] reported that hip abduction strength was significantly weaker on the paretic side of stroke patients' legs than in the nonparetic side and in the legs of healthy controls. Hip abduction was also the most impaired maximal voluntary task among lower extremity tasks [43].

\section{3) Nocturia}

Tabara et al. [47] demonstrated significant differences in the frequency of nocturnal urination between groups divided into hip abduction strength quartiles. In addition, regression analysis indicated that weak hip abduction strength was significantly associated with frequency of nocturnal urination [47].

\section{EXERCISE}

Previous studies examined the effects of several interventions for strengthening the Gmed while preventing relative activation of other muscles in individuals with Gmed weakness. Han et al. [22] reported that unilateral wall-squat showed a significantly greater Gmed/TFL activation ratio compared to unilateral squat, lateral step-down, and front step-down. Baik et al. [50] reported that side-lying hip abduction with anterior log-rolling position showed significantly greater Gmed activation, but significantly less TFL activation than that with neutral position or posterior log-rolling position. Lee et al. [2] also reported that the Gmed/TFL activation ratio was significantly greater in side-lying hip abduction with hip medial rotation than that with neutral hip or lateral hip rotation. The activation ratio of Gmed/TFL was also significantly greater in sidelying hip abduction with hip flexion $15^{\circ}$ or $30^{\circ}$ than $0^{\circ}$ [52].
Dynamic neuromuscular stabilization during side-lying hip abduction rather than abdominal draw-in maneuver or abdominal bracing, showed significantly greater Gmed/TFL activation ratio, significantly lower quadratus lumborum (QL) activation, and significantly faster Gmed-TFL relative muscle onset time [62]. Kim [63] reported that side-lying hip abduction exercise with Thera-Band in the forward bottom leg position showed significantly greater Gmed/TFL muscle activation ratio than the Thera-Band in the neutral bottom leg position or with Thera-Band in the backward bottom leg position. Jeong et al. [3] reported that adding push force of both feet or both heels and metatarsal heads during clamshell exercise showed significantly lower anterior hip flexor muscle activation compared to the standard clamshell exercise. Finally, Lee et al. [64] demonstrated that side bridge exercise with knee flexion showed a significantly higher Gmed/TFL muscle activation ratio than side bridge exercise or side bridge exercise with knee flexion and hip abduction.

\section{DISCUSSION}

During walking and running, the Gmed contracts eccentrically to resist the large external force acting on the joint in the frontal plane [16]. Specifically, hip abduction strength plays an important role in counteracting contralateral pelvic drop and maintaining a semineutral pelvic orientation during the stance phase of gait [65]. However, previous studies have reported that hip abduction strength has no significant correlation with the magnitude of pelvic drop during performance of the Trendelenburg test or during walking; therefore, weak hip abductor strength is not sufficient for a positive Trendelenburg test $[7,38,55]$. Nevertheless, increased center of pressure displacement during dynamic balance tasks due to diminished hip abductor muscle strength may be associated with the risk of ankle injury because the center of pressure sway amplitude has been demonstrated as a predictor of ankle sprain injury [4]. In addition, hip abductor muscle weakness is also associated with risk of potential falls because weak hip abduction strength seems to cause impaired turning motion in individuals with knee osteoarthritis [10].

Strengthening of the Gmed may play an important role in managing hip joint pathologies. Cooper et al. [20] suggested that Gmed weakness is a common clinical feature in individuals with low back pain, myofascial pain, or trochanteric bursi- 
tis. Osborne et al. [8] also reported that, especially in females, difficulty in pelvi-femoral control due to a broader pelvis makes it more prone to injuries related to Gmed weakness, such as patellofemoral pain syndrome or greater trochanteric pain syndrome. In addition, weak Gmed may cause excessive hip adduction; thus, the greater trochanter can be compressed by gluteal tendons which leads to the development of gluteal tendinopathy [11]. However, although external snapping hip or weakness of eccentric hip abduction strength can also be explained by an overload on the gluteals and iliotibial band due to greater net joint moment of hip abduction, further investigations are needed to determine the relationship between snapping hip and hip abduction weakness [16].

Hip abductor weakness also appears to have a close association with knee and ankle joint pathologies. For example, impaired dynamic control of the lower limb resulting from prolonged patellofemoral dysfunction symptoms leads to a compensatory decrease in hip muscle strength [58]. Decreased hip abduction strength is accompanied by altered kinematics such as increased ipsilateral trunk lean, contralateral pelvic drop, hip adduction, and knee abduction during dynamic tasks [25,27]. These altered kinematics can make the ankle vulnerable to injury due to compensatory neuromuscular adaptations at the ankle resulting from reduced postural control [35]. Therefore, hip abduction strength test should be included in screening procedures to assess patellofemoral pain syndrome, anterior cruciate ligament injury, and ankle injuries [34,35,58]. However, Rabelo and Lucareli [66] suggested that weakness of the gluteal muscles may be a result of reduced demand due to a painful knee rather than being the cause of pain in individuals with patellofemoral pain syndrome. Therefore, it cannot be concluded that the strength deficit of hip abductor muscles makes individuals prone to develop patellofemoral pain syndrome [58].

In individuals with low back pain and gluteal tendinopathy, hip abductor strengthening exercises could lead to improved functional outcomes [67]. Kendall et al. [38] also demonstrated that 3 weeks of hip abductor strengthening reduced pain by $48 \%$ in individuals with non-specific low back pain. In particular, Lee et al. [42] suggested that the posterior fibers of the Gmed should be focused on during the rehabilitation of patients with low back pain because the posterior fibers of the Gmed showed significantly lower thickness changes in the chronic low back pain group than in the healthy group.
Hip abductor muscles are also co-activators that can be used for indirect pelvic floor muscle (PFM) training [47]. Therefore, weak hip abductor muscle strength in women might be related to dysfunction of the PFM, which is related to nocturia [47]. In patients with stroke, reduced pelvic stability and limited movement control due to weakness of the Gmed facilitates compensation to address these problems [44]. Unnecessary energies are consumed, and learning opportunities are interrupted due to this compensation [44]. Consequently, hip abductor muscle strengthening should be considered in various rehabilitation sessions.

Janda described "muscle imbalance" as an impaired relationship between muscles prone to weakness and inhibition and muscles prone to tightness or shortness [68]. The Gmed is one of the phasic system muscles prone to weakness whereas the TFL is one of the tonic system muscles prone to tightness as well as early firing and overactivation [68]. Gmed weakness can result in the overuse of TFL as a hip abductor and this relationship can be described as "synergistic dominance" [69]. The TFL fulfills insufficient Gmed activation during hip abduction, which is required for gait and activities of daily living, thus contributing to further weakness of the Gmed due to disuse [52]. Dominant TFL results in the development of a lateral force on the patella, thus, excessive hip internal rotation and lateral patellar displacement are orccured associated with iliotibial band friction syndrome and patellofemoral pain syndrome [22]. Several pathologies such as pain in the lower back and hip, and degenerative hip joint pathology are also associated with a dominant TFL. Reciprocal inhibition (inhibition of the alpha motor neuron of the antagonist muscle related to stimulated inhibitory interneuron by the muscle spindle of the agonist muscle) can be used to inhibit the TFL during exercises (i.e., activation of gluteus maximus) [50,70]. Similarly, lateral instability and impaired movements such as lumbar spine lateral flexion or lateral tilt of the pelvis can be caused by the substitution of QL for a weakened Gmed during exercises [3,69]. Dynamic neuromuscular stabilization during exercises was demonstrated as an effective intervention for preventing QL activation as well as early onset of TFL activation [62]. Therefore, the relative activation of synergist muscles should be considered when prescribing exercises for Gmed strengthening [2]. However, there was a lack of studies that investigated the effects of dynamic exercise in individuals with Gmed weakness. Thus, further studied are needed to determine the effects 
of dynamic exercises in individuals with Gmed weakness for strengthening.

\section{CONFLICTS OF INTEREST}

No potential conflict of interest relevant to this article was reported.

\section{AUTHOR CONTRIBUTIONS}

Conceptualization: SB, HC, SK. Data curation: SB, HC, SK. Formal analysis: SB, HC, SK. Funding acquisition: SB, HC, SK. Investigation: SB, HC, SK. Methodology: SB, HC, SK. Project administration: SB, HC, SK. Resources: SB, HC, SK. Software: SB, HC, SK. Supervision: SB, HC, SK. Validation: SB, HC, SK. Visualization: SB, HC, SK. Writing - original draft: SB, HC, SK. Writing - review \& editing: SB, HC, SK.

\section{ORCID}

Seung-min Baik, https://orcid.org/0000-0001-7885-9374

Seok-hyun Kim, https://orcid.org/0000-0002-0951-0360

\section{REFERENCES}

1. Radzak KN, Stickley CD. Fatigue-induced hip abductor weakness and changes in biomechanical risk factors for runningrelated injuries. J Athl Train 2020;55(12):1270-6.

2. Lee JH, Cynn HS, Kwon OY, Yi CH, Yoon TL, Choi WJ, et al. Different hip rotations influence hip abductor muscles activity during isometric side-lying hip abduction in subjects with gluteus medius weakness. J Electromyogr Kinesiol 2014;24(2):318-24

3. Jeong SG, Cynn HS, Lee JH, Choi S, Kim D. Effect of modified clamshell exercise on gluteus medius, quadratus lumborum and anterior hip flexor in participants with gluteus medius weakness. J Korean Soc Phys Med 2019;14(2):9-19.

4. Lee SP, Powers CM. Individuals with diminished hip abductor muscle strength exhibit altered ankle biomechanics and neuromuscular activation during unipedal balance tasks. Gait Posture 2014;39(3):933-8

5. Pohl MB, Kendall KD, Patel C, Wiley JP, Emery C, Ferber R. Experimentally reduced hip-abductor muscle strength and frontal-plane biomechanics during walking. J Athl Train
2015;50(4):385-91.

6. Vandekerckhove I, Wesseling M, Kainz H, Desloovere K, Jonkers I. The effect of hip muscle weakness and femoral bony deformities on gait performance. Gait Posture 2021;83: 280-6.

7. Valente G, Taddei F, Jonkers I. Influence of weak hip abductor muscles on joint contact forces during normal walking: probabilistic modeling analysis. J Biomech 2013;46(13):2186-93.

8. Osborne HR, Quinlan JF, Allison GT. Hip abduction weakness in elite junior footballers is common but easy to correct quickly: a prospective sports team cohort based study. Sports Med Arthrosc Rehabil Ther Technol 2012;4(1):1-8.

9. van der Krogt MM, Delp SL, Schwartz MH. How robust is human gait to muscle weakness? Gait Posture 2012;36(1):1139.

10. Iijima H, Yorozu A, Suzuki Y, Eguchi R, Aoyama T, Takahashi M. Hip abductor muscle weakness and slowed turning motion in people with knee osteoarthritis. J Biomech 2020;101:109652.

11. Allison K, Vicenzino B, Wrigley TV, Grimaldi A, Hodges PW, Bennell KL. Hip abductor muscle weakness in individuals with gluteal tendinopathy. Med Sci Sports Exerc 2016;48(3):34652.

12. Foch E, Brindle RA, Milner CE. Weak associations between hip adduction angle and hip abductor muscle activity during running. J Biomech 2020;110:109965.

13. Willson JD, Kernozek TW, Arndt RL, Reznichek DA, Scott Straker J. Gluteal muscle activation during running in females with and without patellofemoral pain syndrome. Clin Biomech (Bristol, Avon) 2011;26(7):735-40.

14. Taylor-Haas JA, Hugentobler JA, DiCesare CA, Hickey Lucas KC, Bates NA, Myer GD, et al. Reduced hip strength is associated with increased hip motion during running in young adult and adolescent male long-distance runners. Int J Sports Phys Ther 2014;9(4):456-67.

15. Foch E, Reinbolt JA, Zhang S, Fitzhugh EC, Milner CE. Associations between iliotibial band injury status and running biomechanics in women. Gait Posture 2015;41(2):706-10.

16. Jacobsen JS, Thorborg K, Søballe K, Ulrich-Vinther M. Eccentric hip abductor weakness in patients with symptomatic external snapping hip. Scand J Med Sci Sports 2012;22(6):e140-6.

17. Casartelli NC, Maffiuletti NA, Item-Glatthorn JF, Staehli S, Bizzini M, Impellizzeri FM, et al. Hip muscle weakness in patients with symptomatic femoroacetabular impingement. Osteoar- 
thritis Cartilage 2011;19(7):816-21.

18. Diamond LE, Wrigley TV, Hinman RS, Hodges PW, O'Donnell $\mathrm{J}$, Takla A, et al. Isometric and isokinetic hip strength and agonist/antagonist ratios in symptomatic femoroacetabular impingement. J Sci Med Sport 2016;19(9):696-701.

19. Frasson VB, Vaz MA, Morales AB, Torresan A, Telöken MA, Gusmão PDF, et al. Hip muscle weakness and reduced joint range of motion in patients with femoroacetabular impingement syndrome: a case-control study. Braz J Phys Ther 2020;24(1):39-45.

20. Cooper NA, Scavo KM, Strickland KJ, Tipayamongkol N, Nicholson JD, Bewyer DC, et al. Prevalence of gluteus medius weakness in people with chronic low back pain compared to healthy controls. Eur Spine J 2016;25(4):1258-65.

21. Aminaka N, Pietrosimone BG, Armstrong CW, Meszaros A, Gribble PA. Patellofemoral pain syndrome alters neuromuscular control and kinetics during stair ambulation. J Electromyogr Kinesiol 2011;21(4):645-51.

22. Han HR, Yi CH, You SH, Cynn HS, Lim OB, Son JI. Comparative effects of 4 single-leg squat exercises in subjects with gluteus medius weakness. J Sport Rehabil 2018;27(6):513-9.

23. Ferber R, Kendall KD, Farr L. Changes in knee biomechanics after a hip-abductor strengthening protocol for runners with patellofemoral pain syndrome. J Athl Train 2011;46(2):1429.

24. Bolgla LA, Earl-Boehm J, Emery C, Hamstra-Wright K, Ferber R. Comparison of hip and knee strength in males with and without patellofemoral pain. Phys Ther Sport 2015;16(3):215-21.

25. Nakagawa TH, Moriya ET, Maciel CD, Serrão FV. Trunk, pelvis, hip, and knee kinematics, hip strength, and gluteal muscle activation during a single-leg squat in males and females with and without patellofemoral pain syndrome. J Orthop Sports Phys Ther 2012;42(6):491-501.

26. Herbst KA, Barber Foss KD, Fader L, Hewett TE, Witvrouw E, Stanfield D, et al. Hip strength is greater in athletes who subsequently develop patellofemoral pain. Am J Sports Med 2015;43(11):2747-52.

27. Bley AS, Correa JC, Dos Reis AC, Rabelo ND, Marchetti PH, Lucareli PR. Propulsion phase of the single leg triple hop test in women with patellofemoral pain syndrome: a biomechanical study. PLoS One 2014;9(5):e97606.

28. Alnahdi AH, Zeni JA, Snyder-Mackler L. Hip abductor strength reliability and association with physical function after unilateral total knee arthroplasty: a cross-sectional study. Phys
Ther 2014;94(8):1154-62.

29. Loyd BJ, Jennings JM, Judd DL, Kim RH, Wolfe P, Dennis DA, et al. Influence of hip abductor strength on functional outcomes before and after total knee arthroplasty: post hoc analysis of a randomized controlled trial. Phys Ther 2017;97(9):896903.

30. Hinman RS, Hunt MA, Creaby MW, Wrigley TV, McManus FJ, Bennell KL. Hip muscle weakness in individuals with medial knee osteoarthritis. Arthritis Care Res (Hoboken) 2010;62(8):1190-3.

31. Costa RA, Oliveira LM, Watanabe SH, Jones A, Natour J. Isokinetic assessment of the hip muscles in patients with osteoarthritis of the knee. Clinics (Sao Paulo) 2010;65(12):1253-9.

32. Omori G, Koga Y, Tanaka M, Nawata A, Watanabe H, Narumi $\mathrm{K}$, et al. Quadriceps muscle strength and its relationship to radiographic knee osteoarthritis in Japanese elderly. J Orthop Sci 2013;18(4):536-42.

33. Piva SR, Teixeira PE, Almeida GJ, Gil AB, DiGioia AM 3rd, Levison TJ, et al. Contribution of hip abductor strength to physical function in patients with total knee arthroplasty. Phys Ther 2011;91(2):225-33.

34. Khayambashi K, Ghoddosi N, Straub RK, Powers CM. Hip muscle strength predicts noncontact anterior cruciate ligament injury in male and female athletes: a prospective study. Am J Sports Med 2016;44(2):355-61.

35. Powers CM, Ghoddosi N, Straub RK, Khayambashi K. Hip strength as a predictor of ankle sprains in male soccer players: a prospective study. J Athl Train 2017;52(11):1048-55.

36. McCann RS, Crossett ID, Terada M, Kosik KB, Bolding BA, Gribble PA. Hip strength and star excursion balance test deficits of patients with chronic ankle instability. J Sci Med Sport 2017;20(11):992-6.

37. Szczygieł E, Kotla K, Masłoń A, Golec J, Czechowska D, Staszkiewicz R, et al. Evaluation of relationship between the results of selected tests for muscle strength assessment of the hip abductors. Acta Bioeng Biomech 2018;20(2):125-31.

38. Kendall KD, Schmidt C, Ferber R. The relationship between hip-abductor strength and the magnitude of pelvic drop in patients with low back pain. J Sport Rehabil 2010;19(4):42235.

39. Penney T, Ploughman M, Austin MW, Behm DG, Byrne JM. Determining the activation of gluteus medius and the validity of the single leg stance test in chronic, nonspecific low back pain. Arch Phys Med Rehabil 2014;95(10):1969-76. 
40. Lee JH, An JH, Lee SH, Seo IS. Three-dimensional gait analysis of patients with weakness of ankle dorsiflexor as a result of unilateral L5 radiculopathy. J Back Musculoskelet Rehabil 2010;23(2):49-54

41. Sasaji T, Horaguchi K, Yamada N, Iwai K. Improvement of hip abductor muscle weakness after lumbar decompressive surgery. Ups J Med Sci 2012;117(4):426-9.

42. Lee SW, Kim SY, Yang JM, Park SD. Comparison of difference of the gluteus medius muscle fiber thickness during maximum muscle contraction between chronic low back pain with gluteus medius weakness and healthy subject. J Korean Soc Phys Med 2015;10(1):71-82

43. Sánchez N, Acosta AM, Lopez-Rosado R, Stienen AHA, Dewald JPA. Lower extremity motor impairments in ambulatory chronic hemiparetic stroke: evidence for lower extremity weakness and abnormal muscle and joint torque coupling patterns. Neurorehabil Neural Repair 2017;31(9):814-26.

44. Park JJ. Effects of selective gluteus medius strengthening training through providing feedback on muscle function and balance in chronic stroke patients. Daejeon, Daejeon University, Master's Thesis. 2015.

45. Krautwurst BK, Wolf SI, Heitzmann DW, Gantz S, Braatz F, Dreher T. The influence of hip abductor weakness on frontal plane motion of the trunk and pelvis in patients with cerebral palsy. Res Dev Disabil 2013;34(4):1198-203.

46. Böhm H, Dussa CU, Multerer C, Döderlein L. Pathological trunk motion during walking in children with amyoplasia: is it caused by muscular weakness or joint contractures? Res Dev Disabil 2013;34(11):4286-92.

47. Tabara Y, Ikezoe T, Matsumoto T, Murase K, Setoh K, Funada S, et al. Association of weak hip abduction strength with nocturia in older women: the Nagahama study. Geriatr Gerontol Int 2019;19(10):1010-6.

48. Fredericson M, Cookingham CL, Chaudhari AM, Dowdell BC, Oestreicher N, Sahrmann SA. Hip abductor weakness in distance runners with iliotibial band syndrome. Clin J Sport Med 2000;10(3):169-75.

49. McConnell J. The physical therapist's approach to patellofemoral disorders. Clin Sports Med 2002;21 (3):363-87.

50. Baik SM, Cynn HS, Shim JH, Lee JH, Shin AR, Lee KE. Effects of log rolling position on hip abductor muscles activity during side-lying hip abduction exercise in participants with gluteus medius weakness. J Athl Train 2020. [Epub]. doi: 10.4085/306-20.
51. Lee JH, Cynn HS, Choi SA, Yoon TL, Jeong HJ. Effects of different hip rotations on gluteus medius and tensor fasciae latae muscle activity during isometric side-lying hip abduction. J Sport Rehabil 2013;22(4):301-7.

52. Park H, Cho S. Effect of hip flexion and internal rotation on the hip abductor muscle activity during side-lying hip abduction in subjects with gluteus medius weakness. Phys Ther Korea 2016;23(3):57-67

53. Neumann DA. Kinesiology of the musculoskeletal system: foundations for rehabilitation. 2nd ed. St. Louis: Mosby/Elsevier; 2010;494-5.

54. O'Sullivan K, Smith SM, Sainsbury D. Electromyographic analysis of the three subdivisions of gluteus medius during weightbearing exercises. Sports Med Arthrosc Rehabil Ther Technol 2010;2:17

55. Kendall KD, Patel C, Wiley JP, Pohl MB, Emery CA, Ferber R. Steps toward the validation of the Trendelenburg test: the effect of experimentally reduced hip abductor muscle function on frontal plane mechanics. Clin J Sport Med 2013;23(1):4551.

56. Brindle RA, Ebaugh DD, Willson JD, Finley MA, Shewokis PA, Milner CE. Relationships of hip abductor strength, neuromuscular control, and hip width to femoral length ratio with peak hip adduction angle in healthy female runners. J Sports Sci 2020;38(20):2291-7.

57. Plastaras C, McCormick Z, Nguyen C, Rho M, Nack SH, Roth D, et al. Is hip abduction strength asymmetry present in female runners in the early stages of patellofemoral pain syndrome? Am J Sports Med 2016;44(1):105-12.

58. Thijs Y, Pattyn E, Van Tiggelen D, Rombaut L, Witvrouw E. Is hip muscle weakness a predisposing factor for patellofemoral pain in female novice runners? A prospective study. Am J Sports Med 2011;39(9):1877-82.

59. Hoglund LT, Burns RO, Stepney AL Jr. Do males with patellofemoral pain have posterolateral hip muscle weakness? Int J Sports Phys Ther 2018;13(2):160-70.

60. McCann RS, Bolding BA, Terada M, Kosik KB, Crossett ID, Gribble PA. Isometric hip strength and dynamic stability of individuals with chronic ankle instability. J Athl Train 2018;53(7):672-8.

61. Arab AM, Nourbakhsh MR. The relationship between hip abductor muscle strength and iliotibial band tightness in individuals with low back pain. Chiropr Osteopat 2010;18:1.

62. Kim G. Differential effect of core exercises on motor control 
pattern and muscle activity during side-lying hip abduction test in individuals with gluteus medius weakness. Seoul, Yonsei University, Master's Thesis. 2019.

63. Kim DE. The bottom leg in the forward position can increase gluteus maximus activity and reduce tensor fasciae latae activity during side-lying hip abduction exercise with theraband in subjects with gluteus medius weakness. Seoul, Yonsei University, Master's Thesis. 2018.

64. Lee K. Electromyographic analysis of hip and trunk muscles activity during side bridge exercises in subjects with gluteus medius weakness. Seoul, Yonsei University, Master's Thesis. 2020.

65. Perry J, Burnfield JM. Gait analysis: normal and pathological function. 2nd ed. Thorofare: SLACK; 2010.
66. Rabelo NDDA, Lucareli PRG. Do hip muscle weakness and dynamic knee valgus matter for the clinical evaluation and decision-making process in patients with patellofemoral pain? Braz J Phys Ther 2018;22(2):105-9.

67. Peterson S, Denninger T. Physical therapy management of patients with chronic low back pain and hip abductor weakness. J Geriatr Phys Ther 2019;42(3):196-206.

68. Page P, Frank CC, Lardner R. Assessment and treatment of muscle imbalance: the Janda approach. Champaign: Human Kinetics; 2009;8-48.

69. Sahrmann S. Diagnosis and treatment of movement impairment syndromes. St. Louis: Mosby; 2002.

70. Fox SI. Human physiology. 10th ed. New York: McGraw-Hill; 2007. 